\title{
LA REPERCUSIÓN CIENTÍFICA DE LOS INVESTIGADORES ESPAÑOLES EN SALUD EXILIADOS EN MÉXICO
}

\author{
Miguel Arenas \\ Departamento de Producción Agrícola y Animal, Universidad Autónoma Metropolitana. \\ Unidad Xochimilco, México D. F. \\ Judith Licea de Arenas y Javier Valles \\ Facultad de Filosofía y Letras. Universidad Nacional Autónoma de México. \\ Ciudad Universitaria. México, D. F.
}

\section{RESUMEN}

El conocimiento de la repercusión internacional de la investigación realizada por los científicos españoles en ciencias de la salud, exiliados en México a raíz de la guerra civil, se intenta a través de técnicas bibliométricas. La validez de la fuente utilizada para el acopio de datos, aceptada cotidianamente para la evaluación de la actividad científica, se discute al emplearse para mostrar el reconocimiento del trabajo de los exiliados con fines históricos.

\section{SUMMARY}

Bibliometric techniques are used to attempt to determine the impact of research carry out by the health sciences Spanish scientists that emigrated to Mexico as a consequence of the civil war. The validity of the source of data, currently accepted as the main tool for the evaluation of researchers' published work, for historical purposes, is discussed.

\section{INTRODUCCIÓN}

La primera generación de exiliados españoles llegó a México en 1939, apenas unos lustros después del movimiento revolucionario de 1910. Para esa fecha, ya se había iniciado la institucionalización de la educación pública y la expropiación petrolera se encontraba en marcha, junto con la creación de nuevas instituciones de educa- 
ción superior ${ }^{1}$. México, de esta manera, daba sus primeros pasos hacia la modernidad y se debatía en un ir y venir de ideas e ideologías, ya que las reformas que el gobierno había puesto en marcha afectaban intereses poderosos y contradecían hábitos y costumbres que tiempo atrás habían sido el modelo de desarrollo social. Los movimientos intelectuales, por ejemplo, se encontraban en su plena madurez, pues muchos de sus participantes se habían formado durante la lucha armada, o bien, habían participado directamente en ella ${ }^{2}$.

La política de exilio adoptada por el gobierno mexicano, pese a la oposición que prevalecía, permitió que varios de los intelectuales españoles que llegaron a México se incorporaran a las instituciones de educación superior que ya existían, y que para entonces estaban en expansión. Se ha afirmado que la llegada de los asilados vino a revitalizar y a enriquecer las actividades culturales, científicas y artísticas de la nación que los acogió, y que sus enseñanzas fortalecieron de manera decidida a las ciencias en México, ya que casi no hubo disciplina científica que no se beneficiara de ellos 3 3,4.5.

En las ciencias de la salud, que es el punto de análisis de este trabajo, no se sabe con certeza cuántos médicos, entre otros profesionales de la salud, se incorporaron al país bajo el régimen del asilo. De los 500 médicos que se estima arribaron al país 6 , varios de ellos, algunos ya con una trayectoria científica consolidada, se dedicaron a la investigación.

La contribución de los médicos españoles a la medicina en México ha sido ampliamente reconocida; sin embargo, con el fin de resaltar el quehacer de un puñado de hombres que participaron en el fortalecimiento de la práctica científica en México, se intentó determinar el grado de repercusión de sus contribuciones por medio de una fuente extranjera que es utilizada cotidianamente en la medición del trabajo del investigador.

\section{MATERIALES Y MÉTODOS}

Mediante la revisión documental existente sobre el tema del exilio español en México se elaboró una lista de los transterrados que llegaron al país en 1939 y se

1 Reyes NeVARES, S. (1982), México en 1939. En El exilio español en México, 1939-1982, Salvat: FCE, México. p. 59.

2 Ibid, p. 65.

3 SARUKHÁN KeRmeZ, J. (1991), El exilio español en la UNAM. En Cincuenta años del exilio español en la UNAM, UNAM, México. p. 11-16.

4 DíAZ, J.L. (1991), La enseñanza de los científicos. En Cincuenta años del exilio español en la UNAM, UNAM, México. p. 125-133.

5 LEÓN PORTILLA, A. H. de. (1987), Una gama de encuentros y presencia. En El exilio español y la UNAM. UNAM, México. p. 19-33.

6 GuARNER Dalias, V. (1993), «Contribución a la medicina de México de los médicos españoles de la migración en 1939», Gaceta Médica de México 129, p. 87-92. 
incorporaron a actividades académicas, de investigación o de práctica profesional en el área de la salud ${ }^{7,8,9}$. Sus fechas de nacimiento y muerte, especialidad y, en algunos casos, nombres completos se obtuvieron, principalmente, del trabajo de Matilde Mantecón de Souto ${ }^{10}$.

Con una nómina de 65 investigadores se recurrió al SCISEARCH, índice en línea producido por el Institute for Scientific Information (ISI) que cubre un $90 \%$ de la literatura científica y tecnológica más relevante a nivel internacional y que contiene todos los registros incluidos en el Science Citation Index y algunos del Current Contents. Se consultó el archivo 434 que se refiere a los documentos indizados a partir de 1974 y buscó bajo el campo CR -referencia citada- para proceder a identificar los trabajos de los exiliados que habían sido citados .

Se encontró que las publicaciones de 23 exiliados españoles fueron citadas en diferentes grados.

\section{RESULTADOS Y DISCUSION}

Las citas correspondientes a un total de 255 trabajos publicados por los transterrados, tanto en su país de origen como en el que los acogió, fueron registradas en la base de datos consultada. El número de trabajos citados y el número de citas recibidas por cada autor que se proporcionan a continuación señala una muestra, posiblemente pequeña, del quehacer de los autores exiliados antes de su llegada a México y durante el tiempo que permanecieron activos en el país. De F. Guerra y G. Lafora aparecen registrados sus trabajos previos a su venida a México y los realizados hasta su salida del país (Tabla 1 )

La mayor proporción de los trabajos citados escritos por los autores del exilio correspondió a la categoría de artículos (Tabla 2), los cuales fueron publicados, principalmente, por investigadores de disciplinas tales como la psiquiatría, la farmacología y la fisiología. (Tabla 3).

En dieciocho títulos de revistas mexicanas los autores objeto del estudio publicaron un total de 35 artículos, los cuales fueron citados 64 veces, es decir, cada artículo fue citado, en promedio, en dos ocasiones (Tabla 4). Por lo que respecta a las revistas extranjeras, siete títulos publicaron cinco o más artículos citados, es decir, el 22\% del total de artículos publicados por los autores transterrados (Tabla 5).

7 Cueli, J. (1982), Ciencias médicas y biológicas. En El exilio español en México, 1939-1982. Salvat : FCE, México, p. 495-528.

8 GUARNER DALIAS, V. (1993).

9 LEÓN-PORTILLA, A. H. de. (1987).

10 MANTeCón De Souto, M. (1982), Indice biobibliográfico del exilio español en México. En El exilio español en México, 1939-1982, Salvat / FCE, México, p. 717-878. 
La repercusión de los trabajos de los autores exiliados, medida a través de una fuente que indudablemente tiene sesgos y deficiencias y que pese a ello es utilizada hoy en día para calificar a los científicos mexicanos, no fue elevada de acuerdo con los estándares actuales. Sin embargo, la aportación y valía de los trabajos publicados por un grupo distinguido de exiliados españoles tendría que buscarse, principalmente, en el efecto que causaron sobre los profesionales de la salud que formaron, es decir, los datos que arrojó la búsqueda en el banco de información seleccionado no refleja la calidad de los artículos. Para ello, deberían acompañarse de los juicios de expertos en cada disciplina a fin de evaluar en su justa dimensión la aportación de los exiliados a través de las publicaciones científicas.

TABLA 1

AUTORES EXILIADOS CITADOS EN SCISEARCH

\begin{tabular}{|l|c|c|}
\hline AUTOR & N. ${ }^{\circ}$ TRABAJOS CITADOS & N. ${ }^{\circ}$ CITAS \\
\hline Castañeda, A. & 2 & 44 \\
Carrasco, R. & 2 & 3 \\
Costero, I. & 41 & 217 \\
D’Harcourt, R. & 2 & 2 \\
García, G. & 2 & 4 \\
Guerra, F. & 17 & 44 \\
Lafora, G. & 4 & 84 \\
La Garriga, A. & 9 & 15 \\
López Albó, N.W. & 1 & 1 \\
Márquez, M. & 5 & 8 \\
Méndez, R. & 25 & 262 \\
Morales, A. & 7 & 37 \\
Nieto, D. & 12 & 146 \\
Obrador Alcalde, S. & 90 & 456 \\
Oriol, A. & 6 & 50 \\
Peláez & 6 & 15 \\
Pérez Cirera, R. & 1 & 1 \\
Pi Suñer, J. & 4 & 5 \\
Puche, J. & 1 & 1 \\
Ridaura Sánz, C. & 2 & 4 \\
Rivas Cherif, M.D. & 1 & 1 \\
Rodríguez, R. & 7 & 25 \\
Somolinos, G. & 8 & 10 \\
\hline
\end{tabular}


TABLA 2

TIPOLOGÍA DE LOS DOCUMENTOS CITADOS Y NÚMERO DE CITAS RECIBIDAS

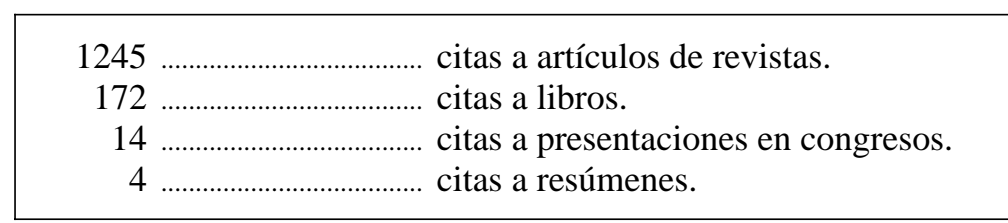

TABLA 3

DISTRIBUCIÓN DE DISCIPLINAS CULTIVADAS

POR LOS AUTORES EXILIADOS

\begin{tabular}{|l|c|}
\hline DISCIPLINA & N. $^{\circ}$ AUTORES \\
\hline Cardiología & 2 \\
Cirugía & 1 \\
Endocrinología & 1 \\
Farmacología & 3 \\
Fisiología & 3 \\
Gastroenterología & 1 \\
Historia & 1 \\
Medicina general & 1 \\
Medicina tropical & 1 \\
Oncología & 1 \\
Oftalmología & 2 \\
Patología & 1 \\
Psiquiatría & 4 \\
Urología & 1 \\
\hline
\end{tabular}


TABLA 4

TÍTULOS DE LAS REVISTAS MEXICANAS QUE PUBLICARON LOS ARTÍCULOS CITADOS

\begin{tabular}{|l|c|c|}
\hline TÍTULO & N. ${ }^{\circ}$ ARTÍCULOS & N. ${ }^{\circ}$ CITAS \\
\hline Arch. I Cardiol. Méx. & 5 & 10 \\
Ciencia & 4 & 8 \\
Prensa Méd. Mex. & 4 & 7 \\
Patología & 3 & 8 \\
An. Soc. Mex. Oftal. & 2 & 3 \\
Gastoenterología & 2 & 2 \\
Neurol. Neurocir. Psiq. & 2 & 2 \\
Rev. Palud. Med. Trop. M. & 2 & 3 \\
Rev. Sanid. Mil. Méx. & 2 & 2 \\
Acta. Méd. Me. & 1 & 1 \\
An. Esc. Nal. Cienc. Biol. & 1 & 5 \\
Arch. Cardiol. Hem. & 1 & 3 \\
Arch. Lat. Am. & 1 & 1 \\
Arch. Neurol. Psiq. & 1 & 1 \\
Gaceta. Méd. Méx. & 1 & 1 \\
Rev. Gastroenterol. Méx. & 1 & 1 \\
Rev. I Enf. Trop. & 1 & 4 \\
Rev. Méd. Hosp. Gral. & 1 & 2 \\
\hline
\end{tabular}

TABLA 5

REVISTAS EXTRANJERAS QUE PUBLICARON CINCO O MAS ARTÍCULOS CITADOS

\begin{tabular}{|l|c|}
\hline TÍTULO & N. ${ }^{\circ}$ ARTÍ́CULOS \\
\hline J. Pharmacol. & 13 \\
Acta Neurochir. & 11 \\
J. Neurosurg. & 10 \\
J. Neurol. Neurosurg. P. & 6 \\
Neurochirurgie & 6 \\
Am. J. Physiol. & 5 \\
J. Urol. & 5 \\
\hline
\end{tabular}

